\title{
EDITORIAL 26.2
}

http://dx.doi.org/10.1590/1984-0292/1346

Apresentamos o volume 26.2 de Fractal: Revista de Psicologia. Nosso periódico tem se adequado às novas demandas da divulgação de conhecimento científico em Psicologia, na interface com outras áreas de conhecimento, valorizando os estudos da subjetividade. Como informado em editorial anterior, contamos com fomento da FAPERJ e da própria Universidade Federal Fluminense, o que tem garantido a cobertura de parte de nosso orçamento.

Além da importância de fomentos como os citados anteriormente, somos uma equipe preocupada com a internacionalização do periódico, sem perder de vista a aposta na qualidade dos manuscritos divulgados e de todo o processo editorial, desde a submissão em nossa plataforma, passando pela avaliação por intermédio de Blind-review, pelo diálogo com autores de manuscritos e alcançando a publicização de pesquisas atuais e concernentes aos campos teórico-metodológicos em que o conceito de subjetividade assuma protagonismo. Nos últimos anos, conseguimos manter a periodicidade de nossa publicação, dialogando com o aumento expressivo de submissões em nossa plataforma online. No volume atual, contamos com contribuições de autores internacionais e de pesquisadores/ autores brasileiros, de diferentes regiões do país.

Temos muitas novidades no ano que segue. Convidamos nossos leitores a compartilhar as pesquisas e reflexões aqui apresentadas. Além disso, frisamos nosso compromisso com a aceleração do processo de divulgação de pesquisas atuais em Psicologia, o que tem produzido importantes efeitos no próprio processo de formação de futuros pesquisadores, em diferentes momentos de sua trajetória. No momento, estamos envolvidos com a preparação dos números subsequentes, sem nos esquecermos do caminho que tanto nos orgulha. Cada volume publicado nos enche de alegria e renova a força do nosso processo editorial, da densidade de nossas apostas teóricas e éticas, além de servir como um dos indicadores da efetividade de nosso funcionamento como equipe. Todo o complexo processo não é visível ao leitor, mas para que os textos se tornem públicos, várias parcerias se consolidaram no nosso tempo de existência. Revisores, diagramadores, consultores ad hoc, professores/pesquisadores, a pós-graduação em Psicologia da UFF/Niterói e a consistente e sábia consultoria de Sérgio Sant'Ana são elementos cruciais para a vida longa de Fractal: Revista de Psicologia. Continuamos firmes em nosso caminho. Boa leitura!

\section{Marcelo S. Ferreira}

Editor 
